\title{
Nonlinear Dynamics Analysis of a Gear-Shaft-Bearing System with Breathing Crack and Tooth Wear Faults
}

\author{
Li Cui* and Chilan Cai
}

Faculty of Engineering, Shanghai Second Polytechnic University, Shanghai, 201209, P.R. China

\begin{abstract}
Considering backlash, time-varying mesh stiffness and radial clearance of bearing, nonlinear dynamic model of gear bearing flexible shaft system is established taking into account breathing crack in shaft and tooth wear. Nonlinear dynamic equations are solved by Runge-Kutta method. Effect of backlash, crack in shaft and tooth wear faults on the nonlinear dynamic behavior of gear-shaft-bearing system is studied. The results show that gear-shaft-bearing system may change from periodic motion to non-periodic motion as backlash increases, and gear pair change from normal mesh to tooth separation, double-sided impact fault. If crack fault appears, quasi-periodic and chaos motion region increases, and gentle crack fault can result in instantaneous tooth separation and double-sided impact faults. Serious tooth wear fault will also induce tooth separation and double-sided impact faults. If both shaft crack and tooth wear faults exist, tooth wear fault will be intensified by double-sided impact fault from shaft crack, which will result in early failure of the gear system.
\end{abstract}

Keywords: breathing crack, gear-shaft-bearing, nonlinear dynamics, tooth wear.

\section{INTRODUCTION}

Nonlinear dynamics behavior of gear-shaft-bearing system has gained great importance. The faults in the system may change dynamic characteristics. If crack fault appears in shaft, it will result in shaft stiffness changes periodically because of opening and closing movement of the crack, which may induce typical non-linear dynamic characteristics in the system. If gear tooth wear fault occurs, mesh stiffness changes and nonlinear dynamics behavior of the system may also be changed.

Many researches have studied the stability and non-linear dynamic analysis of rotor bearing system. Harsha [1] simulated some dynamic response of rotor supported by ball bearings, in his works non-linear dynamic responses were found to be associated with the ball passage frequency and severe vibrations occur when number of balls and waves of outer race are equal. Awrejcewicz [2-4] studied nonlinear characteristics of rotor bearing system using numerical method, instability regions of the rotor system were given for engineering applications. Dynamic behavior of gear-shaftbearing system is more complex because of time-varying mesh stiffness. Dynamic characteristics of gear-shaft-bearing system were studied but the coupling effect of the whole system was often ignored in existing models. Zeman [5] constructed dynamic model of gear system considered backlash, but the shaft was regarded as rigid shaft and only four degrees of freedom was considered. In the following studies [6-8], although the bending and torsion vibration of the gear meshing were considered, but a variety of non-linear

*Address correspondence to this author at the Faculty of Engineering, Shanghai Second Polytechnic University, Shanghai, 201209, P.R. China; Tel: +8621 50216009; Fax: +862150216009;

E-mail: mechcui@163.com factors in the system and the flexible shaft were not considered.

Walha [9] investigated the dynamics of a two-stage gear system involving backlash and time dependent mesh stiffness, which found phenomenon of loss of teeth contact because of the discontinuity of the kinematic movement. Byrtus [10] established a gear system dynamics model using modal synthesis method, in which the time-varying mesh stiffness, side gear clearance, non-linear bearing forces were considered, but impact of flexible shaft was not studied.

Fewer studies were reported on dynamic behavior of gear-shaft-bearing system with faults. Sinou [11] studied the dynamic behavior of rotor system with crack fault and effect of crack depth and location on dynamic characteristics was given. Bajpai [12] constructed dynamic model of gear rotor system considering tooth wear fault, also experiments were performed to verify the model. Lina [13] presented a dynamic model of a plastic gear pair considering tooth wear fault, results show that variation of tooth profiles caused by cumulative sliding wear effect had a significant influence on contact load. Parey [14] developed a six DOF gear dynamic model including localized tooth defect, sinusoidal pulse had been used to simulate the effect of pitting in the gear dynamic model, dynamic responses were solved by differential method, however, effect of faults to the dynamic state of the system were not analyzed.

In this paper, considering breathing crack in shaft and tooth wear faults, nonlinear dynamic model of gear-flexible shaft-bearing system is constructed, in which time-varying mesh stiffness of gear and nonlinear bearing force are also considered. The effects of backlash of gears, breathing crack and tooth wear faults on the dynamic response of the gear system are studied. 


\section{DYNAMIC MODEL OF GEAR-FLEXIBLE SHAFT- BEARING SYSTEM}

\subsection{Dynamic Model of Gear Pair}

Mesh stiffness varied periodically as rotating of gear system. Time-varying mesh stiffness are considered [15]. The gear transmission model is given in Fig. (1). Six freedoms are considered in the model of gear pair, displacements of drive gear and driven gear can be assumed as

$$
\left\{\mathbf{X}_{\mathrm{g}}\right\}=\left\{y_{1}, z_{1}, \theta_{1 x}, y_{2}, z_{2}, \theta_{2 x}\right\}^{T}
$$

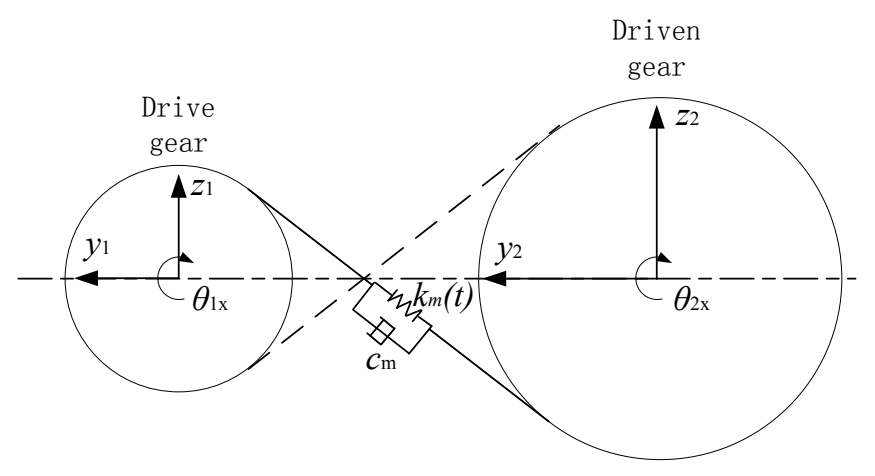

Fig. (1). Model of gear transmission system.

The displacements difference of drive gear and driven gear in the mesh direction is

$$
\Delta d=r_{b 1} \theta_{1 x}+r_{b 2} \theta_{2 x}+\left(z_{1}-z_{2}\right) \cos \alpha+\left(y_{1}-y_{2}\right) \sin \alpha-e_{m}
$$

where, $e_{m}$ is static transmission error of gear system, $\alpha$ is pressure angle of gear. $r_{b 1}, r_{b 2}$ stand for base circle radius of drive and driven gear. Assuming backlash of gears is $2 b_{n}$, time-varying deformation in the mesh direction can be described as piecewise function shown in Fig. (2), and can be written as

$f(\Delta d)=\left\{\begin{array}{cc}\Delta d-b_{n} & \Delta d>b_{n} \\ 0 & -b_{n}<\Delta d<b_{n} \\ \Delta d+b_{n} & \Delta d<-b_{n}\end{array}\right.$

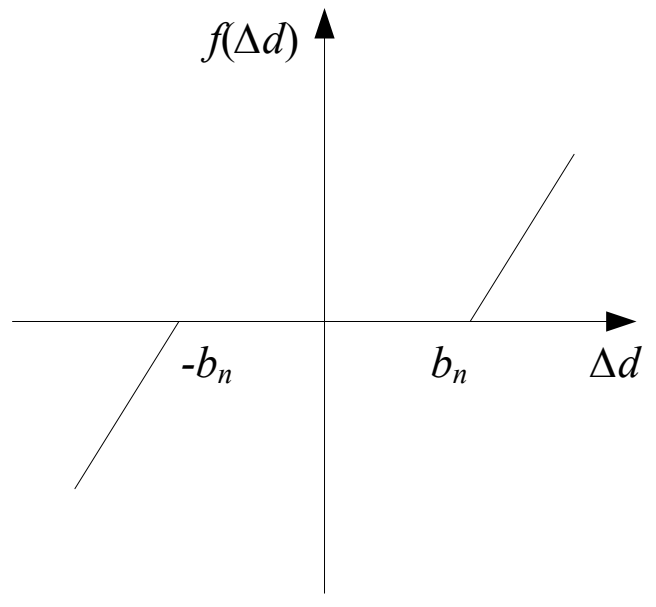

Fig. (2). Function of backlash.
Time-varying meshing force of gear pair can be calculated from the deformation in the mesh direction. Backlash of gear pair may cause tooth separation and tooth impact faults, if $\Delta d>b_{n}$, gear pair can mesh normally, if $-b_{n}<\Delta d<b_{n}$, instantaneous tooth separation fault appears, if $\Delta d<-b_{n}$, tooth back side contact, which is called backsided impact fault. The faults will accelerate tooth wear or tooth broken, which will result in early failure of gear pair.

If displacement response of gear pair in $y$ direction is large enough, both tooth face and tooth back side contact, double-sided impact fault occurs. Double-sided impact will appear when displacements difference in $y$ direction of drive gear and driven gear meet the following requirement

$\Delta y=y_{1}-y_{2}-\frac{b_{n}}{\sin \alpha} \geq 0$

Dynamic model of gear pair can be constructed as

$$
\begin{aligned}
& m_{1} \ddot{y}_{1}=k_{m}(t) f(\Delta d) \sin \alpha+c_{m}\left(\left(\dot{z}_{1}-\dot{z}_{2}\right) \cos \alpha+\right. \\
& \left.\left(\dot{y}_{1}-\dot{y}_{2}\right) \sin \alpha+r_{b 1} \dot{\theta}_{1 x}+r_{b 2} \dot{\theta}_{2 x}-\dot{e}_{m}\right) \sin \alpha \\
& m_{1} \ddot{z}_{1}= \pm k_{m}(t) f(\Delta d) \cos \alpha \pm c_{m}\left(\left(\dot{z}_{1}-\dot{z}_{2}\right) \cos \alpha+\right. \\
& \left.\left(\dot{y}_{1}-\dot{y}_{2}\right) \sin \alpha+r_{b 1} \dot{\theta}_{1 x}+r_{b 2} \dot{\theta}_{2 x}-\dot{e}_{m}\right) \cos \alpha-m_{1} g
\end{aligned}
$$

$I_{1 x} \ddot{\theta}_{1 x}=T_{1} \mp k_{m}(t) r_{b 1} f(\Delta d) \cos \alpha \mp c_{m} r_{b 1}\left(\left(\dot{z}_{1}-\dot{z}_{2}\right) \cos \alpha+\right.$

$\left.\left(\dot{y}_{1}-\dot{y}_{2}\right) \sin \alpha+r_{b 1} \dot{\theta}_{1 x}+r_{b 2} \dot{\theta}_{2 x}-\dot{e}_{m}\right) \cos \alpha$

$m_{2} \ddot{y}_{2}=-k_{m}(t) f(\Delta d) \sin \alpha-c_{m}\left(\left(\dot{z}_{1}-\dot{z}_{2}\right) \cos \alpha+\right.$

$\left.r_{b 1} \dot{\theta}_{1 x}+r_{b 2} \dot{\theta}_{2 x}+\left(\dot{y}_{1}-\dot{y}_{2}\right) \sin \alpha-\dot{e}_{m}\right) \sin \alpha$

$m_{2} \ddot{z}_{2}=\mp k_{m}(t) f(\Delta d) \cos \alpha \mp c_{m}\left(\left(\dot{z}_{1}-\dot{z}_{2}\right) \cos \alpha+\right.$

$\left.\left(\dot{y}_{1}-\dot{y}_{2}\right) \sin \alpha+r_{b 1} \dot{\theta}_{1 x}+r_{b 2} \dot{\theta}_{2 x}-\dot{e}_{m}\right) \cos \alpha-m_{2} g$

$I_{2 x} \ddot{\theta}_{2 x}=T_{2} \mp k_{m}(t) r_{b 2} f(\Delta d) \cos \alpha \mp c_{m} r_{b 2}\left(\left(\dot{z}_{1}-\dot{z}_{2}\right) \cos \alpha+\right.$

$\left.\left(\dot{y}_{1}-\dot{y}_{2}\right) \sin \alpha+r_{b 1} \dot{\theta}_{1 x}+r_{b 2} \dot{\theta}_{2 x}-\dot{e}_{m}\right) \cos \alpha$

where, $m_{1}$ and $m_{2}$ are mass of drive and driven gear. $T_{1}$ and $T_{2}$ are torque of drive and driven gear. $k_{m}(t), c_{m}$ are stiffness and damping of gear pair. When gear mesh normally, the upper signs are used, the nether signs are used when gear back contact occurs.

\subsection{Model of Breathing Crack Fault in Shaft}

Model of shaft cross-section with crack fault is shown in Fig. (3). Where, OYZ is inertial coordinate system, oyz is the moving coordinate system fixed on the rotating shaft.

Dimensionless parameter of crack depth is defined as

$\lambda=\frac{h}{R}$

where, $h$ is crack depth in the shaft, $R$ is radius of the shaft cross-section.

Stiffness of the shaft with crack fault can be obtained by finite element method: 


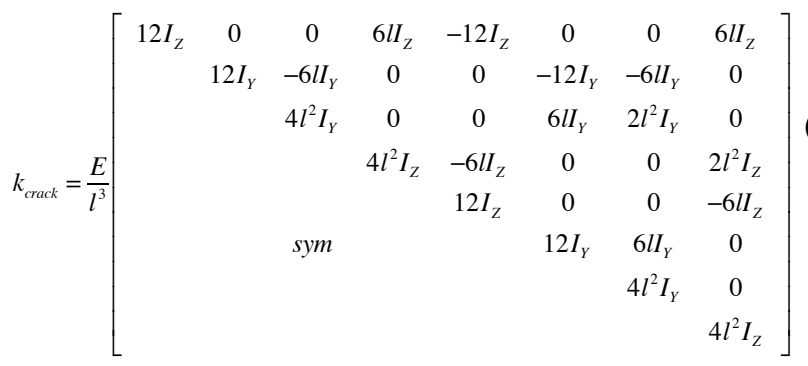

where, $I_{Y}, I_{Z}$ are inertia moment of the shaft about $Y$ and $Z$ axis, respectively. $I_{Y}=I_{\underline{y}}-A \bar{Y}^{2}, I_{Z}=I_{\underline{z}}$. $I_{\underline{y}}, I_{\underline{z}}$ are inertia moment of the shaft about $\underline{y}$ and $z$ axis, $A$ is area of the crosssection without crack, $\bar{Y}$ is distance of mass center of the shaft and mass center of cross-section without crack. $E$ is modulus of elasticity, $l$ is shaft length.

$$
\begin{aligned}
& I_{\underline{y}}=\frac{\pi R^{4}}{8}-\frac{R^{4}}{4}\left((1-\lambda)\left(2 \lambda^{2}-4 \lambda+1\right) \gamma+\sin ^{-1}(1-\lambda)\right) \\
& I_{\underline{z}}=\frac{R^{4}}{12}\left((1-\lambda)\left(2 \lambda^{2}-4 \lambda-3\right) \gamma+3 \sin ^{-1}(\gamma)\right) \\
& A=R^{2}\left((1-\lambda) \gamma+\frac{\alpha}{2}\right), \quad \bar{Y}=\frac{2}{3 A} R^{3} \gamma^{3}, \quad \gamma=\sqrt{2 \lambda-\lambda^{2}} \\
& \alpha=2 \cos ^{-1}(1-\lambda) .
\end{aligned}
$$

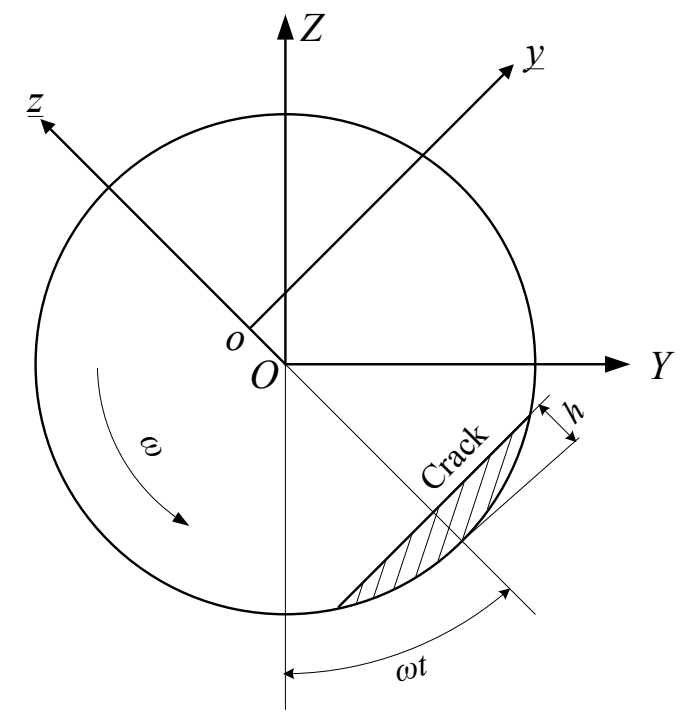

Fig. (3). Model of cracked element cross-section of shaft.

Considering breathing effect of the crack fault, stiffness of the shaft with crack can be written as

$$
K_{\text {Crack }}=\frac{1-\cos \omega t}{2} k_{\text {crack }}
$$

\subsection{Model of Tooth Wear Fault}

Tooth wear fault of gear can be simulated by pulse signal [9]. Rectangle wave pulse can be used to simulate easily but it can not simulate meshing process of the fault gear very well, in this paper, half sine function is used to simulate gear tooth wear fault

$$
G(t)=A_{w} \sin \left(\frac{\omega z}{2} t\right) g(t)
$$

where, $A_{w}$ is amplitude of gear tooth wear fault, which varies in the range of 0 to 1 and is proportional to the wear fault degree. $g(t)$ is periodic pulse function.

$g(t)=\left\{\begin{array}{cc}1 & t_{w} \leq t-n \cdot \frac{2 \pi}{\omega} \leq t_{w}+\frac{2 \pi}{\omega z} \\ 0 & \text { other }\end{array}\right.$

where, $t_{w}=\operatorname{int}\left(\frac{z}{n_{w}} \cdot n_{i}\right) \cdot \frac{2 \pi}{\omega z}, n_{i}=0,1,2, \cdots N_{w}, \quad n_{w} \quad$ is number of teeth with wear fault.

Gear tooth wear affects stiffness of the gear, therefore, mesh stiffness of gears considering wear fault is written as

$k_{\text {wear }}(t)=k_{h} l_{w} G(t)$

where, $k_{h}=\frac{\pi E_{g}}{4\left(1-\mu^{2}\right)}, k_{h}$ is Hertz contact stiffness, $l_{w}$ is wear length, $E_{g}$ is modulus of elasticity of gear teeth, $\mu$ is Poisson's ratio of gear.

\subsection{Dynamic Model of Gear-Flexible Shaft-Bearing System with Faults}

Fig. (4) gives nodes model of gear bearing rotor system, shafts are separate into some segments using finite element method, in which two-nodes Euler element model is used.

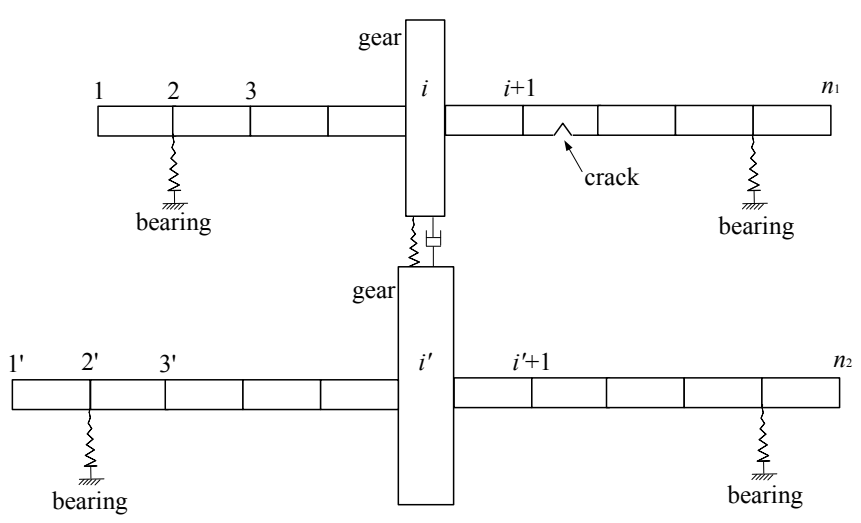

Fig. (4). Nodes of gear bearing rotor system.

Through Euler beam model, mass, stiffness, damping factor, gyroscopic and load matrix of the shaft nodes can be obtained by finite element method. Taking responses as $\boldsymbol{X}=\left[\boldsymbol{X}_{1}, \boldsymbol{X}_{2}, \cdots, \boldsymbol{X}_{n_{1}+n_{2}}\right]$, where $\boldsymbol{X}_{i}=\left\{x_{i}, y_{i}, z_{i}, \theta_{x i}, \theta_{y i}, \theta_{z i}\right\}$. Mass, stiffness, damping factor, gyroscopic and load matrix of the gear bearing system can be obtained by integrated assemble method and finite element method, in which six degrees are considered for every node, the total degrees of every matrix are $6\left(n_{1}+n_{2}\right) \times 6\left(n_{1}+n_{2}\right)$. The method for assembling these matrixes is shown in Fig. (5). 


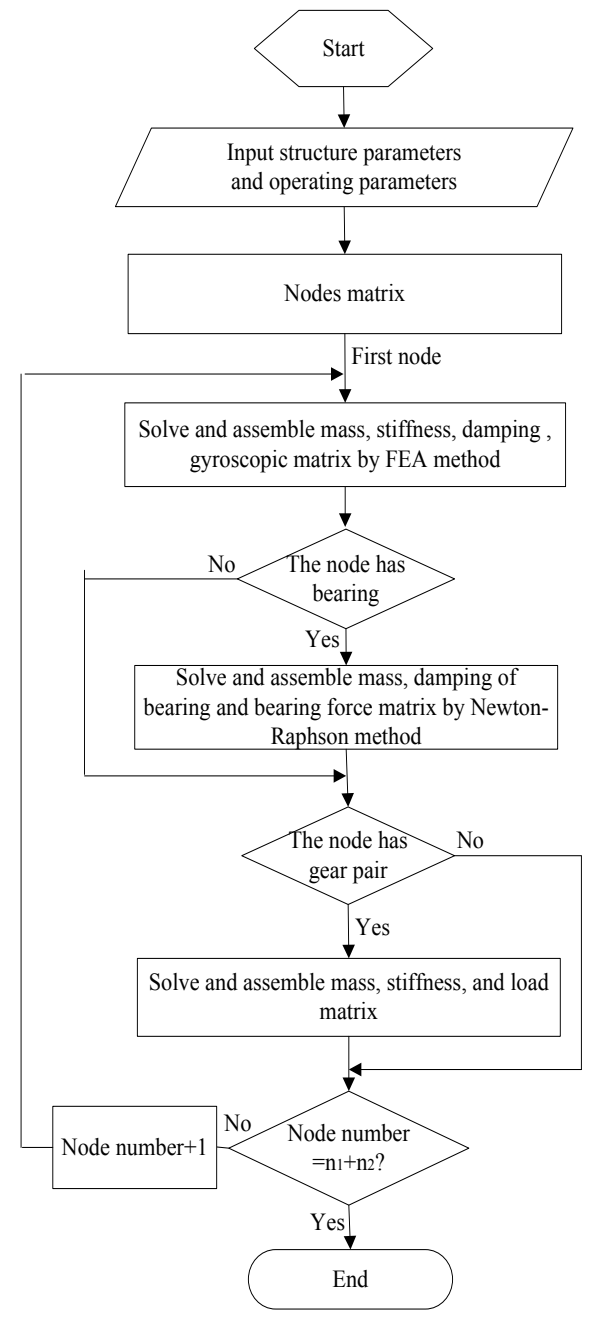

Fig. (5). Integrated assemble method and finite element method.

Taking the far left node of the two shafts as the first node, assemble mass, stiffness, damping and gyroscopic matrix into the integrated corresponding matrixes. If the $i$ th shaft node has crack, then the stiffness matrix should be written as

$K_{i}=K_{i}-K_{\text {crack }}, K_{i+1}=K_{i+1}-K_{\text {crack }}$

If the node is rolling bearing, because of varying compliance vibration in rolling bearing, nonlinear bearing force acting on the shaft should be considered in the dynamic model, which can be obtained by solving bearing equilibrium equations use Newton-Raphson method [16-18]. Assemble mass, damping and nonlinear bearing force matrix are assembled into the integrated corresponding matrixes.

If the node has gear pair, mass, coupling stiffness and load matrix are assembled into the integrated corresponding matrixes, if the gear has tooth wear fault, then the stiffness matrix should be changed as

$k_{m}(t)=k_{m}(t)-k_{\text {wear }}(t)$

When these matrixes finish assembling, dynamic model of gear bearing rotor system with crack and tooth wear faults can be obtained

$$
\boldsymbol{M}\{\ddot{\boldsymbol{X}}\}+(\boldsymbol{C}+\boldsymbol{G})\{\dot{\boldsymbol{X}}\}+\boldsymbol{K}\{\boldsymbol{X}\}=\boldsymbol{P}(t)
$$

where, $\boldsymbol{M}, \boldsymbol{C}, \boldsymbol{G}, \boldsymbol{K}$ are mass, damping, gyroscopic and stiffness matrix. $\boldsymbol{P}(t)$ is load matrix, which including unbalance, nonlinear bearing force, gravity and external force.

\section{CALCULATION METHOD}

There may be a variety of incentive frequency in the gear-shaft-bearing system. Such as meshing of gear pair, time-varying stiffness excitation of bearing and other faults incentives. In order to search periodic solutions, a modified FPA are used to analyze the responses [19], which defines an unified solving time period satisfying the following equation

$$
\begin{aligned}
& T=\kappa T_{g} \\
& \left|\frac{T}{T_{V C}}(\bmod 1)-1\right|<\varepsilon
\end{aligned}
$$

where, $T$ is the time period to solve the response, $T_{g}$ is period of gear meshing, $T_{V C}$ is period of varying compliance frequency of ball bearing, $\varepsilon$ is a very small number. $\kappa=1,2$, $3, \ldots$

Do the calculation until finding a $\kappa$ meet equation (21), then the solving time period can be determined. Runge-Kutta method is used to solve the nonlinear dynamic equations.

\section{RESULTS AND DISCUSSIONS}

Taking a gear-shaft-bearing system as an example, length of two shafts are same as $350 \mathrm{~mm}$, modulus of elasticity is $2 \times 10^{11} \mathrm{~Pa}$, Poisson's ratio is 0.3 , the shafts are supported symmetrically by two 7306 ball bearings. Torque of gear transmission is $200 \mathrm{~N} \cdot \mathrm{m}$. Structural parameters of drive gear and driven gear are shown in Table 1. Every shaft is divided into 5 nodes. Taking response results at gear node, effect of breathing crack and tooth wear faults on the nonlinear response of the system are analyzed.

\subsection{Effect of Backlash on Dynamic Behavior}

Fig. (6) studies effect of backlash on bifurcation responses. If backlash of drive gear and driven gear changes from $60 \mu \mathrm{m}$ to $100 \mu \mathrm{m}$, displacement response amplitude increase and nonperiodic motion speed region increases obviously.

Table 1. Structure parameters of gears.

\begin{tabular}{|c|c|c|}
\hline Parameters & Drive Gear & Driven Gear \\
\hline \hline Tooth number & 40 & 50 \\
\hline Mass $/ \mathrm{kg}$ & 1.82 & 2.13 \\
\hline Module $/ \mathrm{mm}$ & 3 & 3 \\
\hline Pressure angle $/{ }^{\circ}$ & 20 & 20 \\
\hline Radius of base circle $/ \mathrm{mm}$ & 57.3 & 71.6 \\
\hline Moment of inertia $/ \mathrm{kg} \cdot \mathrm{m}^{2}$ & 0.0034 & 0.0017 \\
\hline Backlash $/ \mu \mathrm{m}$ & \multicolumn{2}{|c|}{60} \\
\hline
\end{tabular}


(a) Backlash is $60 \mu \mathrm{m}$

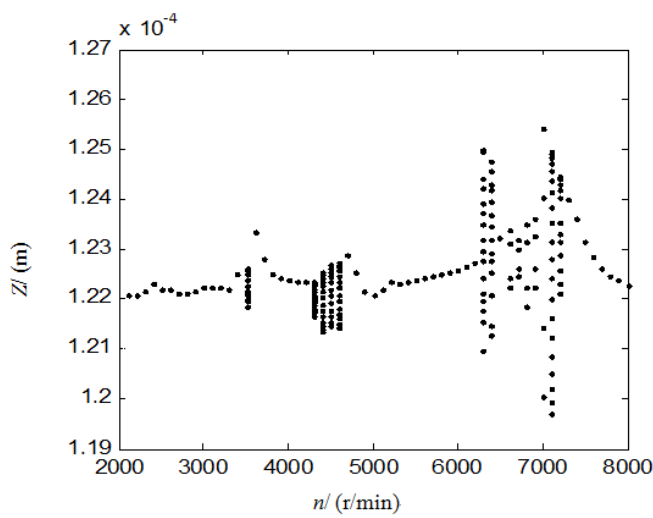

(b) Backlash is $100 \mu \mathrm{m}$

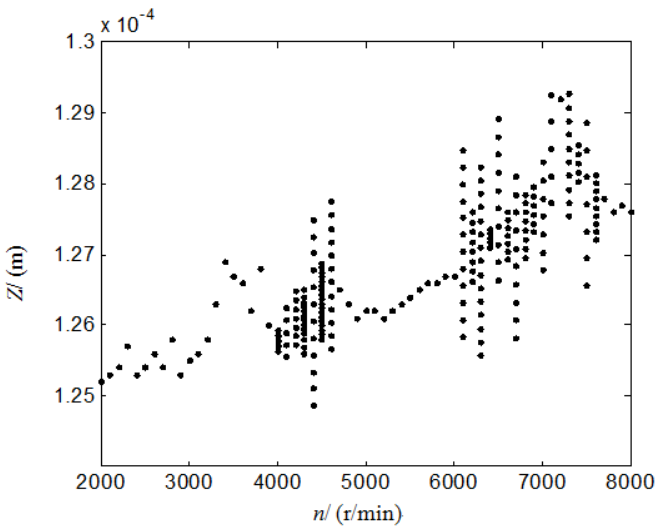

Fig. (6). Bifurcation of responses at gear node as backlash changes.

Fig. (7) shows responses of gear node at $7500 \mathrm{r} / \mathrm{min}$ and backlash of $60 \mu \mathrm{m}$. Fig. (7a, b) indicate that dynamic behavior of gear system is periodic motion, in which $f_{b}$ is varying compliance vibration frequency of bearing, $f_{g}$ is mesh frequency of gear. From formula (3) and formula (4), tooth separation, back-sided impact and double-sided impact faults can be determined. Fig. (7c) shows displacement difference in mesh direction $\Delta d>30 \mu \mathrm{m}$, Fig. (7d) shows $\Delta y$ $<0$, it can be concluded that the gears mesh normally.

Fig. (8) gives responses of gear node at $7500 \mathrm{r} / \mathrm{min}$ and backlash of $100 \mu \mathrm{m}$. Fig. $(\mathbf{8 a}, \mathbf{b})$ indicate that continuous spectrum and irregular map in the Poincare section, it can be known that the system changes into chaos motion. Fig. (8c) shows displacement difference in mesh direction $\Delta d<50 \mu \mathrm{m}$ regularly, Fig. (8d) shows $\Delta y<0$ occasionally, it can be concluded that tooth separation and slight double-sided impact faults appear in the gear system.

\subsection{Effect of Breathing Crack Fault on Dynamic Behavior}

Assuming breathing crack fault occurs in drive shaft, effect of crack depth is analyzed. Fig. (9) gives bifurcation behavior of responses at gear node when crack depth parameter $\lambda$ are 0.5 and 1 . It can be seen that displacement response increase as crack depth increases. Fig. (7) shows periodic motion in most speed region if no crack fault in shaft, however, Fig. (9) demonstrates the speed region of non periodic vibration obvious increase gradually as crack depth increase. (a) Frequency spectrum

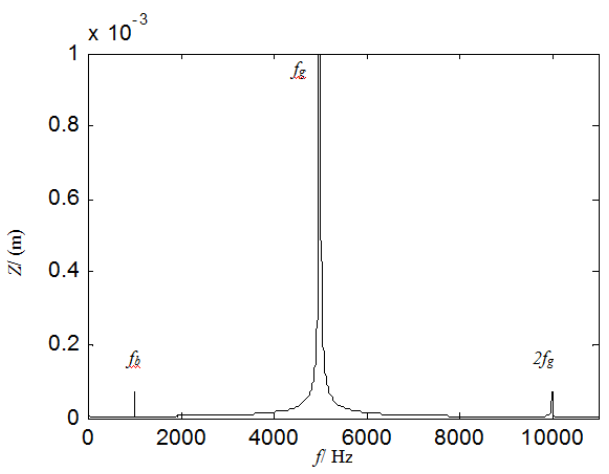

(b) Poincare map

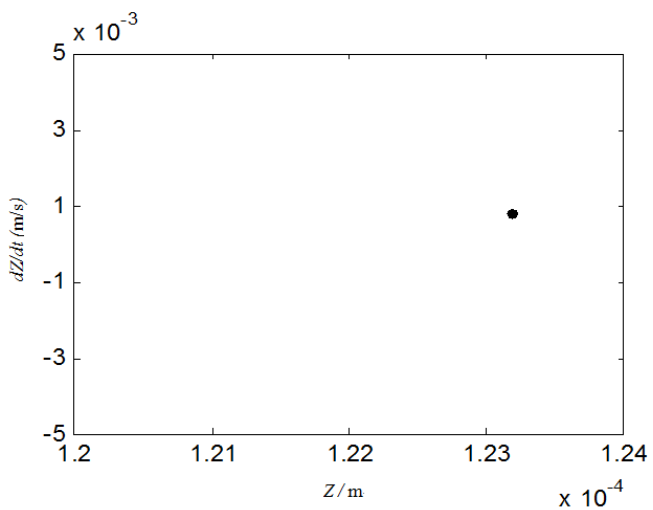

(c) Displacement difference in mesh direction

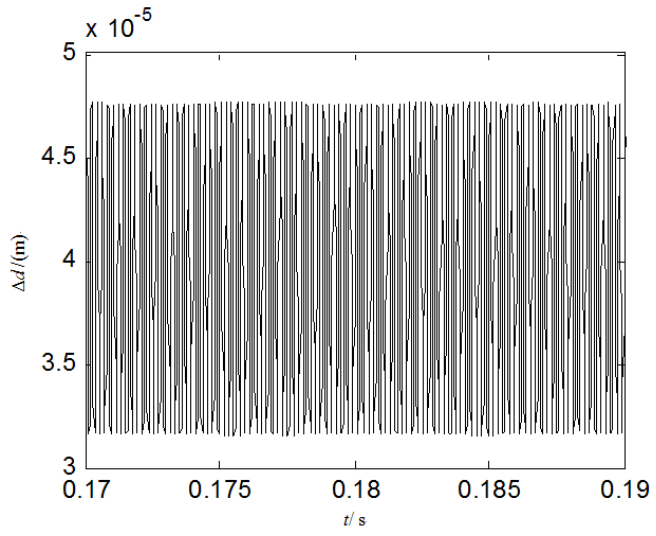

(d) Displacement difference in y direction

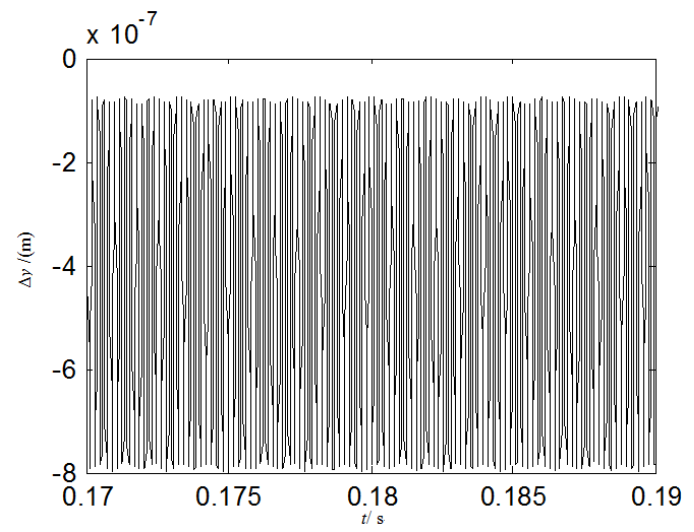

Fig. (7). Responses at $7500 \mathrm{r} / \mathrm{min}$ and backlash of $60 \mu \mathrm{m}$. 
(a) Frequency spectrum

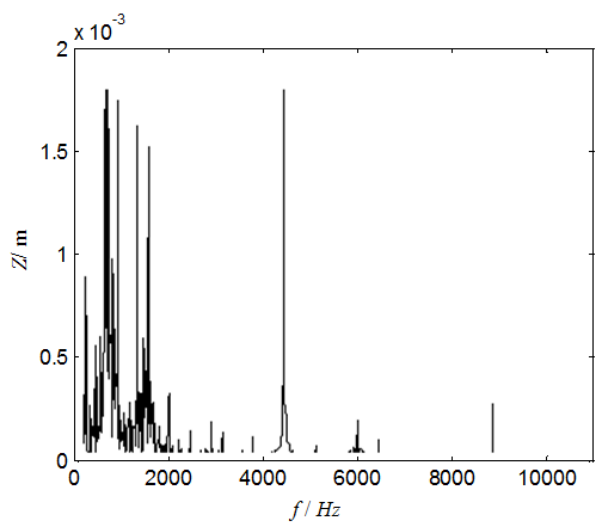

(b) Poincare map

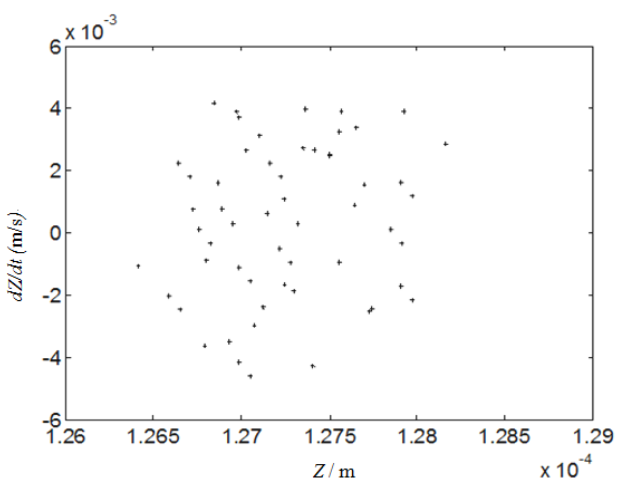

(c) Displacement difference in mesh direction

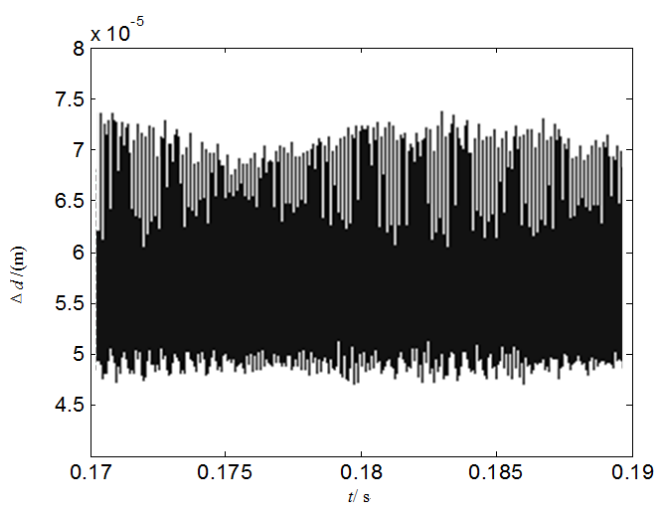

(d) Displacement difference in y direction

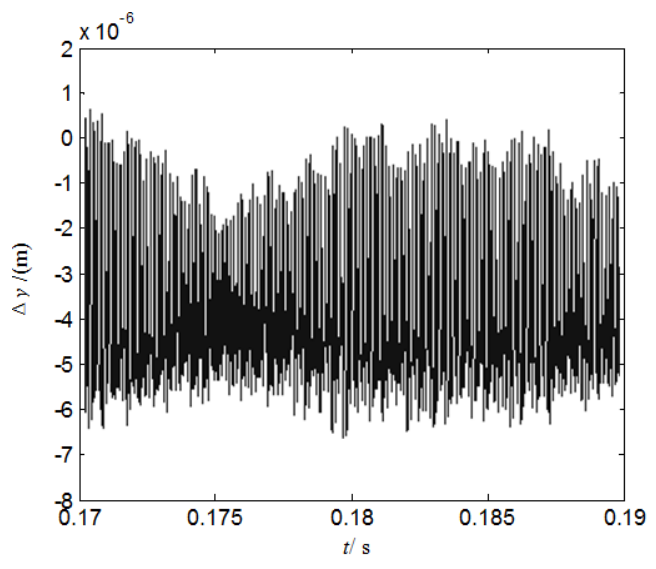

Fig. (8). Responses at $7500 \mathrm{r} / \mathrm{min}$ and backlash of $100 \mu \mathrm{m}$. (a) $\lambda=0.5$

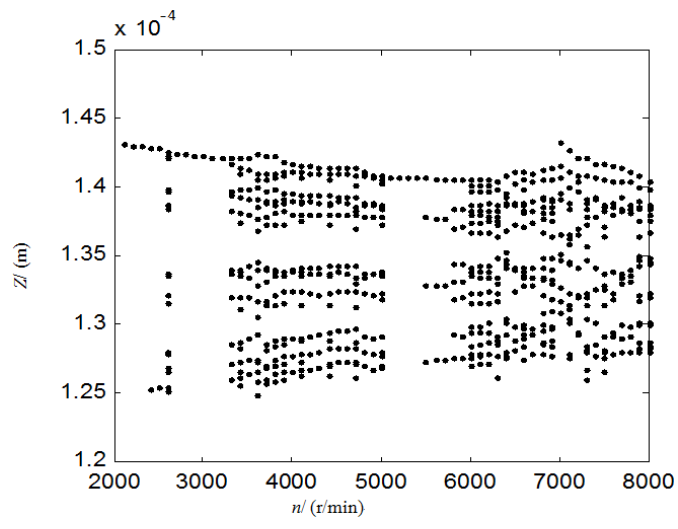

(b) $\lambda=1$

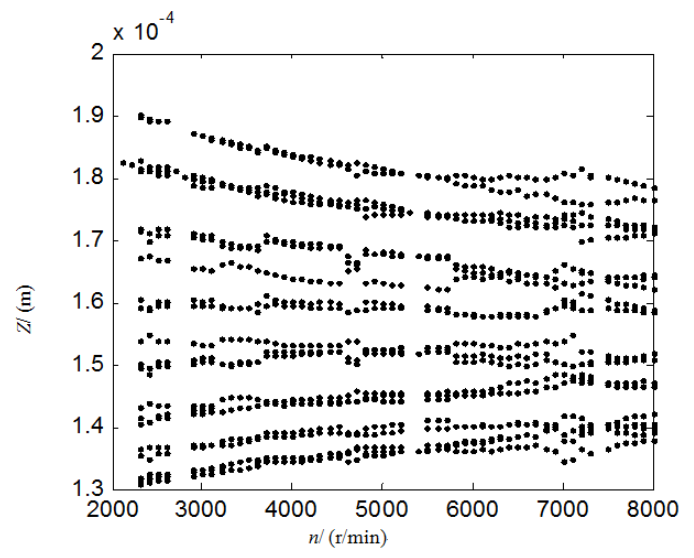

Fig. (9). Bifurcation at gear node as crack depth changes.

Fig. (10) gives response at $7500 \mathrm{r} / \mathrm{min}$ when crack depth $\lambda$ is 0.5 . If there is no crack fault, Fig. (7) indicate that gears mesh normally. When crack depth $\lambda$ is equal to 0.5 , Fig. (10a) shows displacement difference in mesh direction $\Delta d$ $<30 \mu \mathrm{m}$ frequently, it can be known that gently instantaneous tooth separation appears. Fig. (10b) shows displacement increase and $\Delta y>0$, it can be concluded that serious doublesided impact faults occurs, and response changes in cosine function because of breathing action of crack.

Fig. (11) gives response at $7500 \mathrm{r} / \mathrm{min}$ when crack depth $\lambda$ is equal to 1 . When crack depth $\lambda$ is equal to 1 , Fig. (11a) shows displacement difference in mesh direction $\Delta d<30 \mu \mathrm{m}$ regularly, it can be seen that instantaneous tooth separation occurs. Fig. (11b) shows more larger displacement response and more serious double-sided impact faults.

It can be concluded that dynamic behavior of gear bearing system may change from periodic motion into nonperiodic motion when shaft crack fault exist, simultaneously, the gentle crack fault can induce tooth separation and serious double-sided impact faults.

\subsection{Effect of Gear Tooth Wear Fault on Dynamic Behavior}

Assuming there are three tooth in drive gear have wear fault, Fig. (12) gives bifurcation responses at gear node when wear length is $1 \mathrm{~mm}$ and $2 \mathrm{~mm}$. Fig. (12a) shows speed region in non-periodic motion increases compare with Fig. 
(6a). If wear length is increased to $2 \mathrm{~mm}$, Fig. (12b) shows most speed region changes into non-periodic motion.

(a) Displacement difference in mesh direction

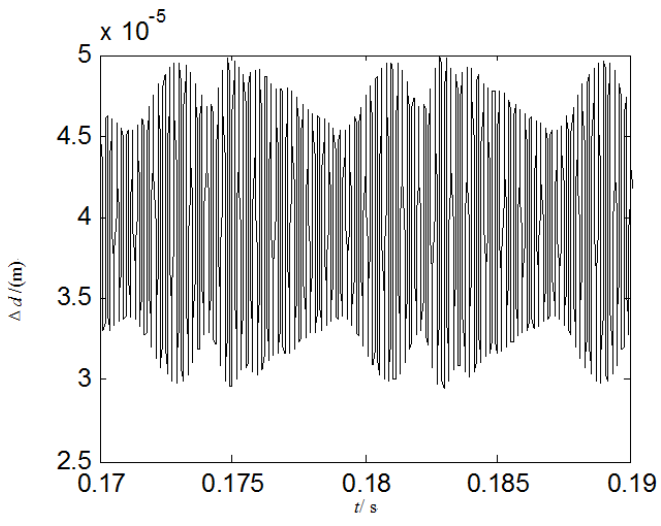

(b) Displacement difference in y direction

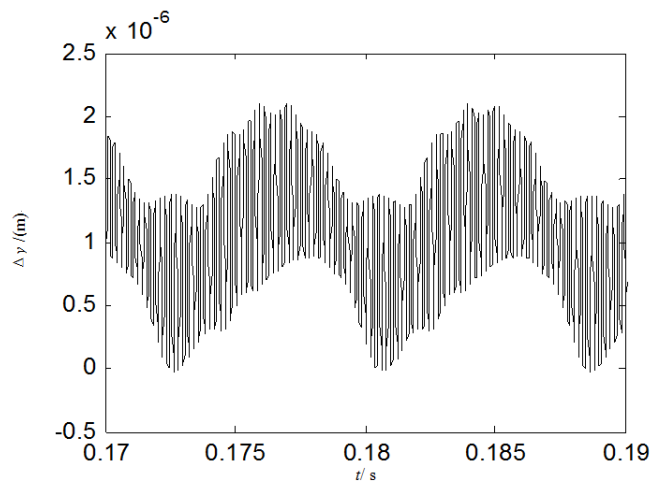

Fig. (10). Responses at $7500 \mathrm{r} / \mathrm{min}$ with crack fault $\lambda=0.5$.

Fig. (13) gives response at $7500 \mathrm{r} / \mathrm{min}$ when tooth wear length $l_{w}$ is $1 \mathrm{~mm}$. Fig. (13a) shows displacement difference in mesh direction $\Delta d>30 \mu \mathrm{m}$, Fig. (13b) shows displacement response $\Delta y<0$, it can be concluded that the gears mesh normally.

Fig. (14) gives response at $7500 \mathrm{r} / \mathrm{min}$ when wear length $l_{w}$ is $2 \mathrm{~mm}$. Fig. (14a) shows displacement difference in mesh direction $\Delta d<30 \mu \mathrm{m}$ regularly, it can be concluded that instantaneous tooth separation occurs. Fig. (14b) shows displacement response increase and $\Delta y>0$ frequently, it can be seen that serious double-sided impact faults occurs, and response changes in periodic function because of pulse excitation action of tooth wear fault.

It can be concluded that dynamic behavior of gear bearing system may change from periodic motion into nonperiodic motion when tooth wear fault exists. The gentle tooth wear fault may not affect gear meshing, serious tooth wear fault will induce tooth separation and double-sided impact faults.

\section{CONCLUSION}

Backlash of gear pair has important effect on dynamic behavior of gear-shaft-bearing system. If backlash is too large, dynamic state of gear system may change from periodic motion to non-periodic motion, and tooth separation, (a) Displacement difference in mesh direction

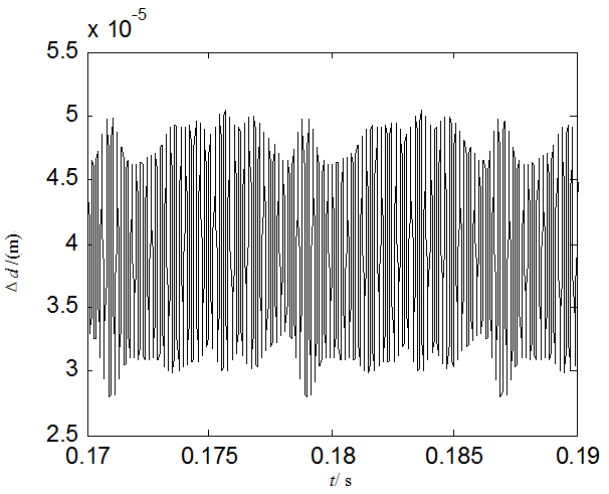

(b) Displacement difference in y direction

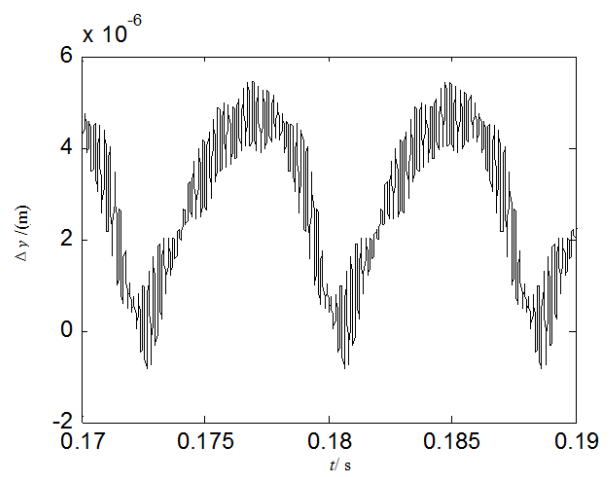

Fig. (11). Responses at $7500 \mathrm{r} / \mathrm{min}$ with crack fault $\lambda=1$.

(a) $l_{w}=1 \mathrm{~mm}$

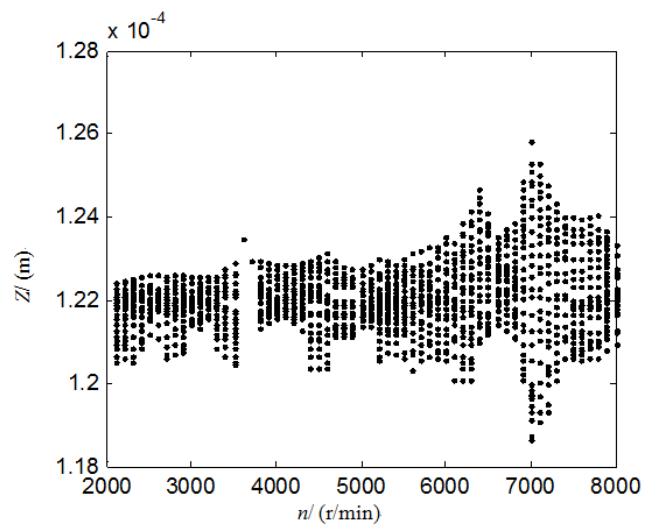

(b) $l_{w}=2 \mathrm{~mm}$

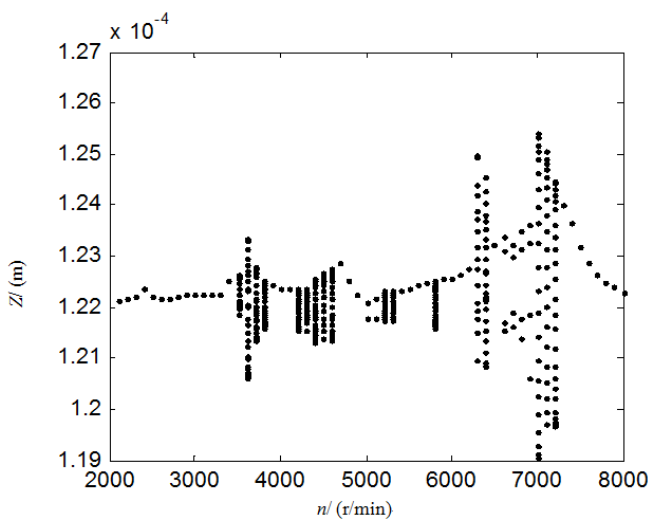

Fig. (12). Bifurcation responses as wear length changes. 
(a) Displacement difference in mesh direction

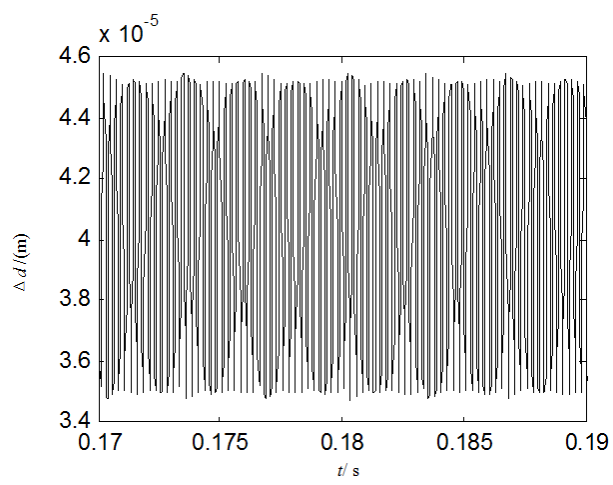

(b) Displacement difference in y direction

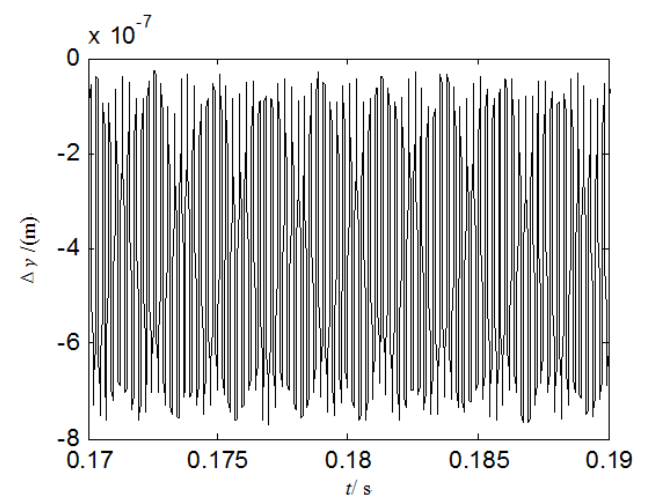

Fig. (13). Responses at $7500 \mathrm{r} / \mathrm{min}$ with wear fault $l_{w}=1 \mathrm{~mm}$.

(a) displacement difference in mesh direction

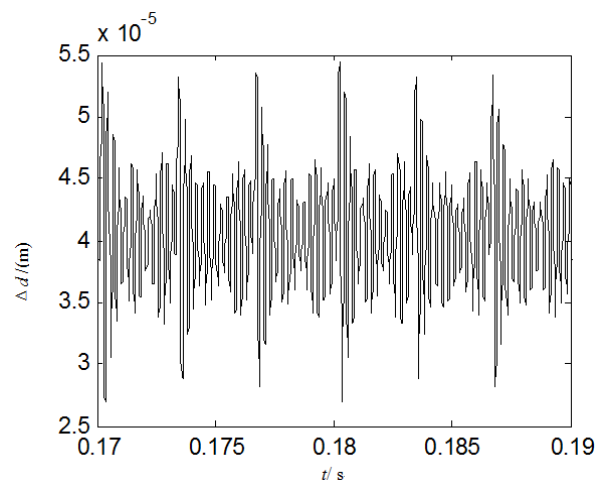

(b) Displacement difference in y direction

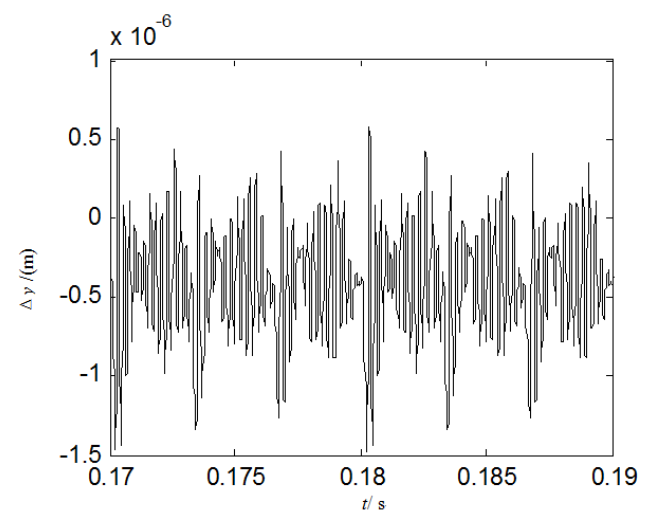

Fig. (14). Responses at $7500 \mathrm{r} / \mathrm{min}$ with wear fault $l_{w}=2 \mathrm{~mm}$. behavior of gear bearing system may change from periodic motion into non-periodic motion when shaft crack fault or tooth wear fault exist. The gentle crack fault can induce instantaneous tooth separation and serious double-sided impact faults. Serious tooth wear fault will also induce tooth separation and double-sided impact faults. If both shaft crack fault and tooth wear fault exist in the gear-shaft-bearing system, double- sided impact fault caused by crack fault will intensify tooth wear fault, which will result in early failure of gear system.

\section{CONFLICT OF INTEREST}

The authors confirm that this article content has no conflict of interest.

\section{ACKNOWLEDGEMENTS}

This work was financially supported by Shanghai Natural Science Foundation (14ZR1416800), Shanghai Alliance Plan (LM201408), Foundation of SSPU (EGD14XQD12), National Natural Science Foundation of China (50905061) and Mechanical Manufacturing and Automation discipline of SSPU (XXKPY1305).

\section{REFERENCES}

[1] P. S. Harsha, K. Sandeep, and R. Prakash, "The effect of speed of balanced rotor on non-linear vibrations associated with ball bearings", Mechanical Science, vol. 45, pp. 725-740, 2003.

[2] J Awrejcewicz, B. Supel, C.-H. Lamarque, G. Kudra, G. Wasilewski, and P. Olejnik, "Numerical and experimental study of regular and chaotic motion of triple physical pendulum", International Journal of Bifurcation and Chaos, vol. 18, no. 10, pp. 2883-2915, 2008.

[3] J. Awrejcewicz, K. Tomczak, and C.-H. Lamarque, "Controlling system with impacts", International Journal of Bifurcation and Chaos, vol. 9, no. 3, pp. 547-553, 1999.

[4] J. Awrejcewicz, and L.P. Dzyubak, "2-dof nonlinear dynamics of a rotor suspended in the magneto-hydrodynamic field in the case of soft and rigid magnetic materials", International Journal of NonLinear Mechanics, vol. 45, no. 9, pp. 919-930, 2010.

[5] V. Zeman, "Vibration of mechanical systems by the modal synthesis method", Journal of Applied Mathematics and Mechanics, vol. 75, no. 4, pp. 99-101, 1994.

[6] M. Byrtus, "Qualitative analysis of nonlinear gear drive vibration caused by internal kinematic and parametric excitation", Engineering Mechanics, vol. 15, no. 6, pp. 471-480, 2008.

[7] W. Cai, and J. Chang, "Strong nonlinearity analysis for gearbearing system under nonlinear suspension bifurcation and chaos", Nonlinear analysis: Real world applications, vol. 11, pp. 17601774, 2010.

[8] T. C. Gupta, K. Gupta, and D. K. Sehgal, "Instability and chaos of a flexible rotor ball bearing system: an investigation on the influence of rotating imbalance and bearing clearance", Journal of Engineering for Gas Turbines and Power, vol. 133, pp. 1-11, 2011.

[9] L. Walha, T. Fakhfakh, and M. Haddar, "Nonlinear dynamics of a two-stage gear system with mesh stiffness fluctuation, bearing flexibility and backlash", Mechanism and Machine Theory, vol. 44, pp. 1058-1069, 2009.

[10] M. Byrtus, and V. Zeman, "On modeling and vibration of gear drives influenced by nonlinear couplings", Mechanism and Machine Theory, vol. 46, pp. 375-397, 2011.

[11] J. Sinou, "Effects of a crack on the stability of a non-linear rotor system", International Journal of Non-Linear Mechanics, vol. 42, pp. 959-972, 2007.

[12] P. Bajpai, A. Kahraman, and E. N. Anderson, "A surface wear model for parallel axis gear pairs”, Journal of Tribology, vol. 126, pp. 597-604, 2004. 
[13] A. Lina, and J. Kuang, "Dynamic interaction between contact loads and tooth wear of engaged plastic gear pairs", International Journal of Mechanical Sciences, vol. 50, pp. 205-213, 2008.

[14] A. Parey. M. El-Badaoui, and F. Guillet, "Dynamic modelling of spur gear pair and application of empirical mode decompositionbased statistical analysis for early detection of localized tooth defect", Journal of Sound and Vibration, vol. 294, pp. 547-561, 2006.

[15] Y. Cai, "Simulation on the rotational vibration of helical gear in consideration of the tooth separation phenomenon", Journal of Mechanical Design, vol. 117, pp. 460-468, 1995.
[16] S.P. Harsha, "Nonlinear dynamic analysis of a high-speed rotor supported by rolling element bearings", Journal of Sound and Vibration, vol. 290, pp. 65-100, 2006.

[17] L. Wang, L. Cui, and D. Zheng, "Study on dynamic property of ball bearing system with nonlinear vibration of rotor", Journal of Mechanical Engineering Science, vol. 222, pp. 1811-1819, 2008.

[18] A. T. Harris, "Rolling Bearing Analysis (4th Edition) ", John Wiley \& Sons, Inc, New York, 2001.

[19] P. Sundararajan, and S. T. Noah, "An algorithm for response and stability of large order non-linear systems application to rotor systems", Journal of sound and vibration, vol. 214, no. 4, pp. 695702, 1998.

(c) Cui and Cai; Licensee Bentham Open.

This is an open access article licensed under the terms of the Creative Commons Attribution Non-Commercial License (http://creativecommons.org/licenses/by-nc/3.0/) which permits unrestricted, non-commercial use, distribution and reproduction in any medium, provided the work is properly cited. 